\title{
Unusually located intrathoracic extrapulmonary mediastinal hydatid cyst manifesting as Pancoast syndrome
}

\author{
Berkant Ozpolat, MD, ${ }^{a}$ Murat Ozeren, $M D,{ }^{b}$ Tolga Soyal, MD, and Ertan Yucel, MD, ${ }^{a}$ Ankara and Mersin, Turkey
}

H ydatid cyst still remains an important problem in developing countries. It can appear in any place throughout the body and is more common in the liver $(75 \%)$ and lung $(25 \%) .{ }^{1}$ The lung is the second most common site of location, but because of its elastic properties, hydatid cyst seldom shows intrathoracic compression signs and symptoms unless the size is too huge. Compression signs and symptoms can be seen when the cyst is located in the extrapleural or mediastinal region. A few cases of hydatid cyst have been reported as a benign cause of Pancoast syndrome in the English literature.

Here we present an unusual compression of extrapleurally located mediastinal hydatid cyst causing Pancoast syndrome.

\section{Clinical Summary}

A 31-year-old woman was admitted to the hospital with a yearlong history of severe arm and neck pain, cough, and a left supraclavicular mass.

Her physical examination revealed left ptosis, myosis, and lack of sweating on the ipsilateral side of the face, which are the signs of Horner syndrome. In the left supraclavicular region a soft painless mass was palpable. On the chest radiograph, she was found to have a left apical lobulated mass, and supraclavicular ultrasonography revealed a liquid-filled apical mass. Further investigation included a computed tomographic scan revealing a cystic mass $86 \times 48 \mathrm{~mm}$ in diameter (Figure 1). In the T1weighted images of magnetic resonance examination, a hypointense mass with regular contours extending above the clavicle was seen (Figure 2, $A$ ), and in the T2-weighted images hyperintense cystic mass lesion with lobulated contours was seen (Figure 2, $B$ ). Serologic test results for hydatid disease were positive. Results of the patient's neurologic examination were normal.

A left posterolateral thoracotomy was performed through the fifth intercostal space, and the mass was identified to be cystic and located extrapleurally in the uppermost portion of the thoracic cavity, extending to the supraclavicular region. Frank adhesions to the apex of the lung were present. After the adhesions had been

From the Department of Cardiovascular Surgery, a Ankara Teaching Hospital Social Security Organization (S.S.K.), Ankara, Turkey, and the Department of Cardiovascular Surgery, ${ }^{\mathrm{b}}$ Mersin University Medical Faculty, Mersin, Turkey.

Received for publication July 8, 2004; accepted for publication July 21, 2004.

Address for reprints: Murat Ozeren, MD, Tip Fakültesi Hastanesi, Zeytinlibahçe caddesi, 33079, Mersin, Turkey (E-mail: mozeren@yahoo.com).

J Thorac Cardiovasc Surg 2005;129:688-9

$0022-5223 / \$ 30.00$

Copyright $\odot 2005$ by The American Association for Thoracic Surgery

doi:10.1016/j.jtcvs.2004.07.047

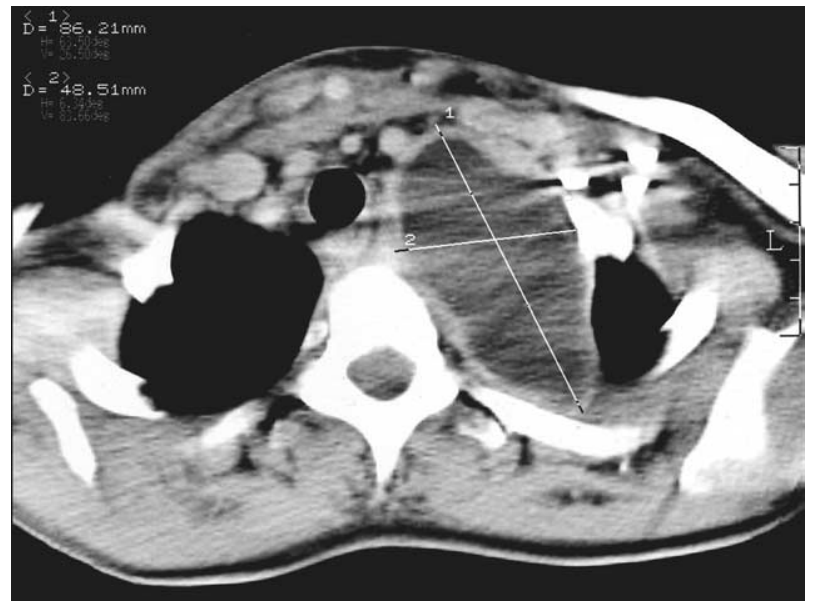

Figure 1. Computed tomographic scan demonstrating a cystic mass $86 \times 48 \mathrm{~mm}$ in diameter.

dissected from the surrounding structures, the intact cyst was inactivated with hypertonic $\mathrm{NaCl}$ solution, cystotomy was performed, and the germinative membrane was removed. The underlining sympathetic chain was identified and freed. Gross and histopathologic examination of the excised operative material also confirmed the diagnosis of hydatid cyst.

Postoperatively, albendazole $\left(10 \mathrm{mg} \cdot \mathrm{kg}^{-1} \cdot \mathrm{d}^{-1}\right)$ therapy was given as our routine medication and continued for 6 months. The postoperative course of the patient was uneventful, and she was discharged on the fifth postoperative day. The arm pain ceased, but the signs of Horner syndrome persisted in the early postoperative period, and only a minimal regression was seen in her third-year examination.

\section{Discussion}

Pancoast syndrome is a constellation of characteristic symptoms and signs that includes shoulder and arm pain along the distribution of the eighth cervical nerve trunk and the first and second thoracic nerve trunks, Horner syndrome, and weakness and atrophy of the muscles of the hand, most commonly caused by local extension of an apical lung tumor at the superior thoracic inlet. ${ }^{2}$

Hydatid cysts can be located in various tissues, although mediastinal hydatid disease has been rarely reported in the literature. ${ }^{3}$ When it is located in the mediastinum, compression signs might be seen because of the close relation to the adjacent vascular or neural structures.

Horner syndrome caused by any segment of the 3-neuron oculosympathetic pathway injury consists of pupillary myosis, eyelid ptosis, enophthalmous, and facial anhidrosis on the same side of the face. The second neuron of the oculosympathetic pathway can be injured in the upper thoracic cage as a complication of extrapleural masses. ${ }^{4}$ 

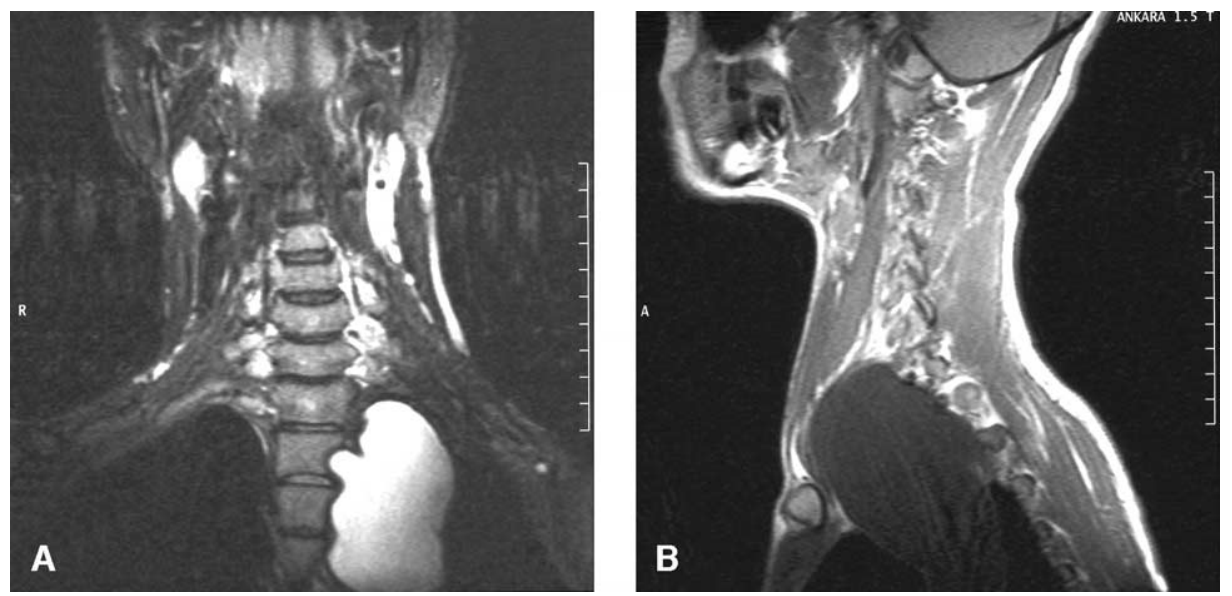

Figure 2. A, T1-weighted left parasagittal image of magnetic resonance examination showing a hypointense mass lesion extending above the clavicle. B, T2-weighted coronal image of magnetic resonance examination showing a hyperintense cystic mass lesion.

Direct pressure of the hydatid cyst on the sympathetic chain on the medial portion of the apex was considered to be the causative factor. Fleishman and colleagues ${ }^{5}$ pointed out that there is a thin endothoracic fascia between the parietal pleura and stellate ganglion. This anatomic feature explains the occurrence of Horner syndrome in the apical thoracic injuries.

The primary treatment of pulmonary hydatid disease is surgical intervention to relieve compression over neurologic structures; however, chemotherapy is used as a complement to operative treatment to avoid recurrence. ${ }^{1}$ Complete cure for cervicobrachial neuralgia was achieved by means of surgical intervention, but Horner syndrome showed minimal regression in our case.

This case report demonstrates that hydatid cysts might cause Pancoast syndrome, and it should be kept in mind in the differential diagnosis of malignant thoracic lesions in patients, especially those living in regions with inadequate hygienic environments and veterinarian control.

\section{References}

1. Dogan R, Yuksel M, Cetin G, et al. Surgical treatment of hydatid cysts of the lung: report on 1055 patients. Thorax. 1989;44:192-9.

2. Pancoast HK. Superior pulmonary sulcus tumour: tumour characterized by pain, Horner's syndrome, destruction of bone and atrophy of hand muscles. JAMA. 1932;99:1391-6.

3. Lucandri G, D'Elia G, Chiavelatti L, et al. Unusual location of hydatid cysts: clinical and therapeutic aspects. Giorn Chirurg. 1994;15:529-37.

4. Slamovits TL, Glaser JS. The pupils and accommodation. In: Glaser JS, editor. Neuro-opthalmology. Philadelphia: JB Lippincott; 1990. p. 459-86.

5. Fleishman JA, Bullock JD, Rosset JS, et al. Iatrogenic Horner's syndrome secondary to chest tube thoracotomy. J Clin Neuro-optho. 1983; 3:205-10. 